\title{
Father-Absence in Anne Tyler's Dinner at the Homesick Restaurant ${ }^{1}$
}

\author{
Shaden Adel Nasser \\ Assistant Professor of English Literature \\ Faculty of Women for Arts, Science \&Education \\ Ain Shams University \\ shaden3900@gmail.com
}

\section{Abstract:}

Fathers occupy a serious role in adolescents' development. The psychological effect of a father's absence to his family deters development of offspring from early childhood, through adolescence and into adulthood. Thus, the present paper is concerned with one type of the disrupted families, the father-absent family. This plentiful and complicated theme, in relation to the psychological and behavioral development of children and adolescents, is central in Anne Tyler's most legendary novel Dinner at the Homesick Restaurant (1982). Accordingly, the aim of this study is to probe the dynamics of the dysfunctional family in Tyler's novel focusing on the psychological aftermaths of the sudden abandonment of the father and living in a mother-headed family on the development of the adolescent son, Cody. A contextual understanding of family-systems theory (FST), literature on sudden, unexpected events, father-absence and mother-headed families guided this study. Accordingly, the case study provides the opportunity to answer the following questions: To what extent father absence has any unique behavioral and psychological effects upon adolescents in this family and what are the psychological outcomes of the sudden, unexpected departure of a father on the solo mother.

Keywords: Anne Tyler, dysfunctional family, abandonment, desertion, fatherless families.

How could you do that? ...How could you just dump us on our mother's mercy? ...We were kids, we were only kids, we had no way of protecting ourselves. We looked to you for help. We listened for your step at the door so we'd be safe, but you just turned your back on us. You didn't lift a finger to defend us. (Cody Tull in Dinner at the Homesick Restaurant 300)

\footnotetext{
${ }^{1}$ An earlier version of this paper was presented at The Third European Conference on Literature and Librarianship. Brighton, United Kingdom in 2016.
} 


\section{Introduction}

Family is the principal social unit, forming humans from their early infancy, where parents play a central role in determining the development of their children. The parent-child relationship provides balance in a sexual, emotional and intellectual way like no other can. During the 1950s, Murray Bowen, along with other American psychotherapists, began exploring the significance of the family on a person's emotional and behavioral development and developed the family systems theory (FST). According to Bowen, a family is a system in which each member had a role to play and rules to respect. He saw the nuclear family as the most basic unit in society. The theory is a concept of looking at the family as a cohesive emotional unit in which individuals can be understood in terms of their relationships with the people in their family. Describing the characteristics of the family systems, Michael E. Kerr and Murray Bowen in Family Evaluation (1988), note that:

The emotionally determined functioning of the family members generates a family emotional "atmosphere" or "field"; that, in turn, influences the emotional functioning of each person. It is analogous to the gravitational field of the solar system, where each planet and the sun, by virtue of their mass, contribute gravity to the field and are, in turn, regulated by the field they help create. One cannot "see" gravity, nor can one "see" the emotional field. The presence of gravity and the emotional field can be inferred, however, by the predictable ways planets and people behave in reaction to one another. (54-55)

The above analogy shows that individuals within one family cannot be understood in isolation from one another, but rather as part of an emotional system. This emotional process results in people's occupying different functioning positions in a family. Hence, as James D. MacArthur suggests, a family where "people feel like they can grow together as individuals within the family environment" is characterized as a functional family (12). From a family-systems perspective, in a functional family, parents clearly define roles and responsibilities they mutually agree upon and are mostly interested in what they can offer their children. All changes in the family system are linked with maintaining its balance. Disorders related to the disruption of relationships between members of the family system, their emotional ties, interpersonal communication and the strategy and family roles. 
The most acquiescent way by which to perceive the intricacies of Bowen family systems is via its eight interlocking concepts: (1) Triangles (2). Differentiation of Self, (3) Nuclear Family Emotional Process, (4) Family Projection Process, (5) Multi-Generational Transmission Process, (6) Sibling Position, (7) Emotional Cutoff, and (8), Emotional Processes in Society. Each of these concepts operates, at least to some degree, in every family. What is related to the present study is Bowen's third concept in which 'the nuclear family' manages differentiation and anxiety with conflict, distance, over and under functioning exchange, which at extremes can lead to dysfunction in a spouse, and child focus. Bowen identified three categories of dysfunction resulting chronic anxiety in a nuclear family emotional system: (1) marital conflict, (2) dysfunction in one spouse, (3) impairment of one or more children and (4) emotional distance (Goldenberg \& Goldenberg 179).

Contrary to the functional family is the 'dysfunctional family' ${ }^{2}$ which is defined by Vincent N. Parrillo, as "a family pattern generationally associated with lower levels of health, well-being, happiness, and positive outcomes, compared with other families". As Raymond M. Jamiolkowski notes, in Coping in a Dysfunctional Family (1998), the only thing all dysfunctional families have in common is their inability to meet the needs of all their members. He states:

A family should provide the basic necessities of life such as food, shelter, and clothing; safely and security from danger; love and belonging; self-esteem; growth; the skills needed for independent living. If a family member is significantly lacking in any of these factors, that family is dysfunctional. (129)

One of the dysfunctional parental acts is the father abandonment for his responsibilities as head of the family. Accordingly, the paper will be divided into two parts. The first part provides a general overview of father-absence as an example of a dysfunctional family pattern and its effects on the members of the family. This is followed by a psychoanalytic study of the impact of the absence of Beck Tull, the father, in Anne Tyler's Dinner at the Homesick Restaurant (1984), on the solo mother, Pearl Tull and the development of their adolescent son, Cody.

\footnotetext{
2 The McGraw-Hill Concise Dictionary of Modern Medicine defines the term 'dysfunctional family' as "a family with multiple 'internal' conflicts. e.g. sibling rivalries. parent-child conflicts. domestic violence. mental illness. single parenthood. or 'external' conflicts, e.g. alcohol or drug abuse, extramarital affairs, gambling, unemployment-influences that affect the basic needs of the family unit".
} 
A father-son relationship is a unique bond and attachment that can be one of the most significant and powerful relationships in an individual's life, i.e. a special relationship that can shape childhood development, influence values and be a prognosticator of both positive and negative psychological well-being in adolescence and adulthood. Over the past two decades, an increasing amount of attention has been paid to the widespread threat of paternal deprivation, including various forms of father-absence such as, nonparticipation, abrupt separation and abandonment. The absence of the father figure in the family is becoming a common occurrence in America today. According to the U.S. Census Bureau ${ }^{3}, 19.7$ million children, more than 1 in 4 , live without a father in the home producing juvenile aggression, depression and family relationship problems. Hence, this statistic data propels the present paper to pursuit the negative aftermaths of father-absence on offspring's psychological well-being throughout his life course.

Father- absence is a term that is not well defined and much of the psychological literature does not distinguish between father-absence due to death, parental relationship discord or other causes. That is why the term 'father-absence', according to Leah East, Debra Jackson, and Louise O'Brien, can incorporate a variety of conditions, "a father who is non-existent in one's life, lost through death, divorce or family discord, absent through work commitments, absent from the family residence due to incarceration or institutionalization, or physically present yet absent due to disinterest or neglect" (285).

Dennis A. Balcom, in his "Absent Fathers: Effects on Abandoned Sons", defines absent fathers as "those who, in the process of leaving the family, do not offer explanations to their children about the reasons for their departure. The other dominant attribute of this type of father is that he does not stay in contact with his children or, again, offers reasons for his continuing disconnection from them. The children thus abandoned feel their fathers are mysteriously, enigmatically, cryptically, or secretively absent" (285). Balcom further adds that father-absence is obsessive and harshly affects the abandoned son's ability for self-esteem and intimacy. For the purposes of this study, father-absence is defined in the light of Balcom's view.

Father-absence as a result of family breakdown and discordance can result in changed family ideals and negative parental behaviors which can be transmitted to the second generation and is termed as "intergenerational transmission" (Parrillo

${ }^{3}$ Source: 2017. U.S. Census Bureau. 
356). There is substantial evidence, based on studies by H.B. Biller in "Father absence, divorce and personality development" (1981) and K.A. Camara and G. Resnick in "Interpersonal conflict and cooperation: Factors moderating children's post children's post-divorce adjustment" (1988), that boys and girls respond differently to a father's departure from the home. In addition, Rachel Levy-Shiff in "The Effects of Father Absence on Young Children in Mother-Headed Families" posits that "boys in mother-headed families would tend to experience more difficulty than girls" (1401) and are generally more aggressive in their disrupting behaviors and more commonly follow rebellious attitudes.

Psychologists such as, P. L. Adams, J. R.Milner, N. A. Schrepf, in Fatherless children (1984), D. Blankenhorn in Fatherless America: Confronting our most urgent social problem (1995) and E. M. Hetherington in Effects of paternal absence on sex-typed behaviors in Negro and white predominant males (1966), agree that the most commonly mentioned causes of paternal absence occurs when a father travels due to financial needs. For those children who are dealing with a temporary loss, such as one due to work, fewer negative effects have been recognized to father-absence. However, according to W. F. Horn in Father facts (2002) and L. Steinberg in Susceptibility of adolescents to antisocial peer pressure (1989), a more severe impact is found on the child's emotional development when the father deserts the family which is one of the most prolonged interpersonal traumatic stressors. According to various psychological studies, the exposure to interpersonal trauma ${ }^{4}$ can chronically and pervasively alter social, psychological, cognitive, and biological development" (D'Andrea 187). It can be said that, children who grow up without their fathers may come to reject paternal-figures due to their experience of being abandoned. These feelings occur with a lack of trust and result in a heightened sense of anger. Moreover, growing into adolescence, these problems may contribute to contact with interpersonal dilemmas including the inability to develop strong social bonds. Likewise, "adult sons abandoned by their fathers have difficulty developing and sustaining self-esteem, forming lasting emotional attachments, recognizing their feelings, or being expressive with their adult partners and children" (Balcom 283). Furthermore, Wade C. Mackey and Bonnie Mackey observe "violent behavior" as a consequence of father-absence (64), including depressive symptoms, delinquency and antisocial behavior.

\footnotetext{
4 The term 'interpersonal trauma' refers "to the range of maltreatment, interpersonal violence, abuse, assault, and neglect experiences encountered by children and adolescents, including familial phy sical, sexual, emotional abuse and incest; community , peer-, and school-based assault, molestation, and severe bullying; severe physical, medical, and emotional neglect; witnessing domestic violence; as well as the impact of serious and pervasive disruptions in caregiving as a consequence of severe caregiver mental illness, substance abuse, criminal involvement, or abrupt separation or traumatic loss" (D'Andrea 188).
} 
What deepens the effect of the abandonment of fathers on the offspring, in some cases, is the mystery of the absence, rather than the natural absence due to work or death. That is why, the unexplained reasons about why the father left cause the son to blame himself for the father's absence and question his own worth to others. Additionally, the father-absence ruins the sons' ability to develop and withstand positive self-esteem and to form successful relationships with adult romantic partners. For Balcom, the abandoned son procures an intense mistrust of the stability and permanency of relationships. Later in adulthood, the abandoned son usually has relationship difficulties with his parents, siblings, chosen partners, and his children missing "the model of a nurturing father" (288). Thus, as Anda Maria Jurma suggests, existence of emotional warmth, support, adequate monitoring and discipline of the adolescent are important protecting factors that can interfere in the process of resilience in adolescents with a solo mother and absent father (78). The following section tackles the effect of father-absence on the solo mother.

A breakup in relationship is certainly the most terrible situation for a person that results into an emotional hindrance. Several studies on women note that "Divorce leads to poor psychological and physical health in women" (Pachauri 207). Pooja Rathiand Pachauri observes that:

After divorce informants faced different type of problems such as: higher rates of anxiety, depression, anger and self-doubt, social rejection... economic hardships, harassment and exploitation, problems related to emotional attachment, psychological problems such as: depression, health problem ...trauma, feeling loneliness and lack in confidence. (208)

According to Thomas S. Parish and Bruno M. Kappes the mother in a fatherless family:

is often required to fulfill multiple roles like homemaker, child-rearer and breadwinner. Her role as the solo parent is made even more difficult by the fact that she need to function many times on a reduced income, lowered social status, and diminished confidence in herself. Besides her own feelings of resentment, isolation and self-doubt, the mother in the father-absent family is frequently struggling with feelings of doubt regarding how she should raise her children. (108) 
A data-based study, by Anda Maria Jurma, observes that mothers that have experienced a divorce or sudden breakup present significantly higher intensity symptoms in the areas of somatization, depression, hostility and phobic anxiety than mothers that have not experienced a divorce. Jurma adds that these symptoms "have a strong influence on the children; especially the symptoms of depression and somatization seem to strongly affect children from divorced families, increasing their level of emotional problems (77). This is also asserted, by Deanna Linville in "A longitudinal analysis of parenting practices, couple satisfaction, and child behavior problems." (2010), that children that are raised by depressive mothers may have symptoms of depression, anxiety, alcohol problems or poor social relationships. Additionally, the stress of living with a depressed parent, is characterized by more negative and unpredictable parental behaviors, and "less parental warmth, more psychological control in parenting and children's greater internalizing and externalizing problems, peer exclusion and reduced prosocial behavior" (Cummings, Keller and Davies 483). However, Barber and Eccles noted that being raised by a single mother can have positive results on adolescent psychological well-being resulting from positive role modelling, maintaining positive adaptive coping mechanisms, demonstration of personal strength and financial independence. This, consequently, can result in adolescents pursuing financial autonomy and having high career aspirations. The following section deals with the analysis of Anne Tyler's Dinner at the Homesick Restaurant in the light of the psychological review.

Anne Tyler, (born 1941), is considered one of America's most important living novelists and short-story writers, whose most novels are marked by details of domestic life. She is a prolific writer whose novels span half a decade. Her descriptions of modern Southern life won her many readers, and Dinner at the Homesick Restaurant (1982), one of her best known works, was a national best seller. After Dinner at the Homesick Restaurant, few critics would deny her importance in contemporary fiction. Throughout Tyler's novels, characters struggle to negotiate a balance between self-identity and family identity. Her portrayal of the American family, especially the deterioration of family structure and the older domestic virtues are major themes in many of her works of fiction. Her fiction is often associated to John Updike's works. Their fiction "centers on family, focusing on the household, the quotidian, and the requirements of the inner circle" (Norton 1). Eileen Battersby, in her review Anne Tyler: the human face of America, praises her skill in relying "on the emotional responses of characters that are as real and as troubled, as flawed and as normal as ordinary people tend to be" (The Irish Times). 
Dinner at the Homesick Restaurant was nominated for the National Book Critics Circle Award in 1982. It was the book that made Anne Tyler famous, and it remains one of her best. Initial critical response to Dinner at the Homesick Restaurant has been overwhelmingly positive. Most reviewers seem to share Benjamin DeMott's enthusiasm over what he calls an "extremely beautiful book: "Funny, heart-hammering, wise, it edges deep into truth that's simultaneously (and interdependently) psychological, moral and formal - deeper than many living novelists of serious reputation have penetrated" (1). Gay Dillon describes the novel "a joy to read" (14). Priscilla Johnson praises a "wise and heartwarming story written with sensitivity and humor, by one of America's finest contemporary novelists" (132).

The setting, as in many of Tyler's fictions, is Baltimore. Eighty-year-old Pearl, the mother of Cody, Ezra, and Jenny Tull, opens chapter one with a series of flashbacks, daydreams, and fantasies that describe her courtship, marriage, and separation. The novel is told by a third person narrator which allows the author to move easily from one character's thoughts to another's and to move back and forth in time. Tyler uses a circular approach to tell Pearl's story, one that begins and ends with Pearl on her deathbed. Pearl's memories not only allow the reader to comprehend how the events of her life have affected and led to her maturation, but they also show the interrelation the actions and characters' lives. She is a desperate, lonely person born an orphan and is deserted by her husband after twenty years of marriage. On her deathbed she ponders over the fact she has no friends and even her children are dosed off from her.

The novel presents the departed father, Beck Tull; a travelling salesman, whose absence makes life difficult for his nuclear family. He abruptly announces to Pearl that he's leaving without any explanation and disappears from her life into the Midwest, saying he doesn't want to see the children after he's gone. The children, at the time of his departure, were fourteen, eleven, and nine. Pearl gets a job as a grocery store checkout clerk to support the family. The sense of abandonment, of having been wronged, is most acute in Pearl and Cody. Thus, the analysis focuses on the aftermaths of the father's absence on psyche of the mother, Pearl, and the behavioral development of the adolescent son.

Her memories range from Cody's attack with croup in 1931, to meeting and marrying the younger, "flamboyant" travelling salesman, Beck Tull, when she was 
thirty years old, already an old maid according to her cousins, to Beck's abrupt declaration in 1944, after twenty years of marriage, that he didn't want to stay married. When Beck abandons her and their three children years later, she responds by drawing a kind of iron curtain around them allowing no degree of intimacy or emotional honesty with anyone outside her close family. Even her own relatives are kept in the dark about Beck's desertion.

Contrary to Bowen's view of a "functional family" as a system wherein each member plays a specific role and must follow certain rules, Tull's family in Dinner at the Homesick Restaurant proves to be a typical "dysfunctional family" characterized by a lack of stability and satisfying basic needs. For the reader, Beck's desertion of his parental role is understandable since from the very beginning of the novel he is presented as being "the invisible man" and "the absent presence" who is not involved in his family life (Anne Tyler 20). His recurrent absence in the most critical moments of the family is explicitly mentioned in the early pages of the novel. He is described as being "so busy with the Tanner Corporation, away from home more often than not, and even when home always fuming over business" (Anne Tyler 4). One terrible night when Cody's breathing was choked and rough, Pearl stayed awake alone till the morning and "Beck was away on business" (Anne Tyler 3). Once, when Beck was "away on business", Pearl walked around with a broken arm for a day and a half till he could come and stay with babies. Thus, this marriage proves to be doomed lacking any real collaboration or empathy. The father's repeated absence paves the way for an eternal leaving which has a negative impact on the mother's psyche and behavior towards her children and which also distracts the children's well-being.

Recalling Anda Maria Jurma's, Pearl suffers from "depression, hostility and phobic anxiety" after the separation. Her depressive feelings and anxiety because of her husband's absence are evident in her dreams and fantasies, for instance, at "nights...she lay in bed in the dark and listened to the gritty click of heels on the sidewalk. Footsteps would come close and then pass. She would let out her breath. A new set of footsteps approached. Surely this was Beck" (Anne Tyler 10). Missing the absconded Beck, Pearl always dreams of him returning back. Once she dreams that he "was new and wonderful again...He gazed at her adoringly, overturning some unfamiliar center deep inside her. He helped her cross streets, climb step... She felt cherished" (Anne Tyler 13). Her dream shows feelings of insecurity and yearning for the husband's support and presence which leads to feelings of depression every time she finds out that this is a dream. 
Feeling overburdened with responsibility after Beck's departure being "preoccupied with paying the rent and juggling the budget and keeping those great, clod-footed children in new shoes" (20), results in high levels of "depression" and "hostility" in Pearl's behavior which consequently leads to more negative and unpredictable parental behaviors. That is why; Pearl becomes "an angry sort of mother...continually on edge... [Feeling] too burdened, too much alone on her behavior towards her children" (19), she frequently loses her temper, "snapped, slapped the nearest cheek, said things she later regretted" (14). Pearl sees herself as a "difficult" mother that she sometimes carries on "like a shrew" (63). Pearl believes that in striving to raise three children alone she acts out of weakness and anxiety, overwhelmed by the responsibilities of motherhood. For as she once told Cody, "How scary it is to know that everyone I love depends on me! I'm afraid I'll do something wrong" (63). Psychologically, her traumatic experience affects her parenting behavior, being less affectionate, less communicative and more punishing in her relation with her children. Moreover, her "phobic anxiety" is shown in her effort to hide her husband's absence from relatives and neighbors trying on every occasion to keep remarking that Beck is doing well and sends them his regards. Her "phobic anxiety" is best expressed when "neighbors showed up, people she knew more closely, she felt she was dying inside but she didn't lose her composure...If she allowed herself to think, she started worrying" (Anne Tyler 15).

Moving to Cody Tull, during adolescence, the analysis attempts to examine how his father's desertion affects his behavioral and emotional development. The reader learns that he becomes aware of Beck's absence earlier than Pearl suspects, and moreover, he is aware of the way Pearl herself behaves to hoard clues about his father's desertion:

One weekend their father didn't come home, and he didn't come the next weekend either, or the next. Or rather, one morning Cody woke up and saw that it had been a while since their father was around. He couldn't say that he had noticed from the start. His mother offered no excuses. Cody, watchful as a spy, studied her furrowed, distracted expression and the way that her hands plucked at each other. It troubled him to realize that he couldn't picture his father's most recent time with them. Trying to find some scene that would explain Beck's leaving, he could only come up with general scenes, blended from a dozen repetitions: meals shattered by quarrels, other meals disrupted when Ezra spilled his milk, drives in the country where his father lost 
the way and his mother snapped out pained and exasperated directions. (40)

The above account shows to what extent the discrepancy between what Pearl thinks the children know and what they actually know marks a severe absence of communication in the mother-child relationship.

One of the outcomes of a father absence is the sense of "guilt" which is patent in Cody's words to the nonexistent father: "Was it something I said? Was it something I did? Was it something I didn't do, that made you go away?" (Anne Tyler 47). He struggles to understand the reason for his father's abandonment. His problem results from his unspoken guilt over his father's departure causing "low self-esteem" and questions about his own worth to others. This sense of guilt is also expressed through his dreams. In Cody's dreams, Cody is a toddler, trying to impress his father, "See this? And this? See me somersault? See me pull my wagon? (Anne Tyler 47). He also imagines if his father returns sometime in the future, when Cody is a man posturing in front of his father to prove that he could make it on his own without Beck's presence in his life. He wishes he could tell him "Look at what I've accomplished ... Notice where I've got to, how far I've come without you" (48).

Confronting his mother about his father's absence, Pearl remarks, "My,...you're getting so big! I can't believe it... You're getting big enough for me to start relying on." "Cody answers her, "I'm only fourteen" (Anne Tyler 42). In the light of psychology, Cody's experience of being abandoned by his father, as well as his fear from the implications of the burden placed on him by his mother's statement "you' re getting big" lead to increased levels of behavioral disorders by a series of cruel childhood pranks against his brother, Ezra, drinking, hanging out with "cheap" girls and getting "arrested over Halloween" (Anne Tyler 58).

It is observed that Cody is the most disturbed soul of his siblings. He suffers from his mother's anger and her emotional detachment after his father's departure and longs for Pearl to be more motherly both in appearance and personality. He compares his mother to the mothers of his friends and was aggrieved of the difference, "he longed to see her gossiping with a little gang of women in the kitchen, letting them roll her hair up in pincurls, trading beauty secrets, playing cards" (Anne Tyler 59). 
The emotional dissolution and brutal nature of the "depressed" mother is shown in Pearl's being bad-tempered, abusive, and violent during meals, throwing a spoon at Cody, yanking Jenny's hair, dumping a bowl of peas over Ezra and "slamming things around and talking to herself... [and] throwing pots through windowpanes" (Anne Tyler 50). Jenny's vivid and condemning description of her mother's rage emphasizes "the interpersonal trauma" the children come through and the reality of Pearl's instability and tendency to use violence toward them:

Jenny knew that, in reality, her mother was a dangerous person-hot breathed and full of rage and unpredictable. The dry, straw texture of her lashes could seem the result of some conflagration, and her pale hair could crackle electrically from its bun and her eyes could get as small as hatpins. Which of her children had not felt her stinging slap, with the claw-encased pearl in her engagement ring that could bloody a lip at one flick? Jenny had seen her hurl Cody down a flight of stairs. She'd seen Ezra ducking, elbows raised, warding off an attack. She herself, more

than once, had been slammed against a wall, been called "serpent," "cockroach," "hideous little sniveling guttersnipe.(70)

Her "negative", "unpredictable" and violent behavior, recalled by Cummings, Keller and Davies, has negative outcomes on her children and are associated with high levels of their hostility, anxiety and aggression that is markedly revealed in Cody's desire to "run away from home" (Anne Tyler 51) and also, in his description of his mother, on the day of her funeral, as a "raving, shrieking, unpredictable witch":

She slammed us against the wall and called us scum and vipers, said she wished us dead, shook us till our teeth rattled, screamed in our faces. We never knew from one day to the next, was she all right? Was she not? The tiniest thing could set her off. 'I' $m$ going to throw you through that window,' she used to tell me. 'I'll look out that window and laugh at your brains splashed all over the pavement. (294)

As the story unfolds, the children grow up and establish lives of their own. Jenny become successful adults: Cody is an efficiency expert, Ezra owns his own restaurant, and Jenny is a pediatrician. And when Cody becomes so successful, he buys the new house [his mother] "had been renting all these years and presented 
her with the deed one Christmas morning" (Anne Tyler 21). Such compensation is a result of the desperate attempts of the "father-absent boy", Cody, to "maintain a masculine identification when no masculine role model is present" (Hetherington 236). Cody's "behavioral disorder" continues up to his adulthood when he steals Ezra's fiancée Ruth. Cody succeeds in winning her heart and marries her to the dismay of Ezra as part of his hostile nature towards his brother. Cody and Ruth have a son named Luke. In a manner similar to Beck, he distances and estranges himself from both his mother and his siblings. This revisits Parrillo's "intergenerational transmission" in which dysfunctional and negative parental behaviors can be transmitted to the second generation. Successful in his business, he is, though, restless and unsatisfied, and he fails to build a strong and healthy relationship with his son, Luke or his wife. This recalls Balcom's view that the father-absence ruins the adult sons' capability to improve positive and successful relationships with their partners or children.

\section{Conclusion}

The present study found emotional and behavioral problems in adolescents from father absent families and also a strong connection between these problems and the behavior of the abandoned mothers. Findings from the analysis of the novel point to the importance of father presence in adolescents' lives and suggest that fatherabsence has social, psychological and behavioral ramifications such as, depression, hostility and aggression.

In Dinner at the Homesick Restaurant (1982), most of the depressive and abusive behaviors of the deserted mother, Pearl, towards her children, are related to the stress of raising a family alone. Cody, representing "the father absent boy" living in a "mother-headed family" whose childhood is damaged by father-absence and the mother's failure to communicate love and empathy, yields to an adulthood filled with disappointment and disorder. Both Pearl and Cody offer a plausible psychological study and insight into the Bowen's family systems theory and the adverse effect of dysfunctionality of a member of the family represented by the father, Beck Tull. 


\section{Works Cited}

Amato, Paul R. "The consequences of divorce for adults and children." Journal of marriage and family 62.4 (2000): 1269-1287.

Barber, Bonnie L., and Jacquelynne S. Eccles. "Long-term influence of divorce and single parenting on adolescent family-and work-related values, behaviors, and aspirations." Psychological Bulletin 111.1 (1992): 108.

Bates, Chris, and Jennifer Teska. "Aband oned children." (2017).

Battersby, Eileen. "Anne Tyler: the human face of America". The Irish Times. 2018

Balcom, Dennis A. "Absent fathers: Effects on abandoned sons." The journal of men's studies 6.3 (1998): 283-296.

Becvar, Dorothy S. "Surprised by Divorce: Working with the Spouse for Whom the Rejection Was Unanticipated." When Marriages Fail: Systemic Family Therapy Interventions and Issues (2007): 195.

Chisholm, Kate, Radio review: "Dinner at the Homesick Restaurant: the genius of Anne Tyler; Don't Log Off”, The Spectator, 25 May 2013.

Cummings, E. Mark, Peggy S. Keller, and Patrick T. Davies. "Towards a family process model of maternal and paternal depressive symptoms: Exploring multiple relations with child and family functioning." Journal of Child Psychology and Psychiatry 46.5 (2005): 479-489.

D'Andrea, Wendy, et al. "Understanding interpersonal trauma in children: Why we need a developmentally appropriate trauma diagnosis." American Journal of Orthopsychiatry 82.2 (2012): 187.

De Mott, Benjamin. "Funny, Wise', and True." The New York Times Book Review, 14 March 1982.

Dillon , Gay Andrews, "Meaty Fiction with a Draft of Sadness," Christian Science Monitor, 9 July 1982.

East, Leah, Debra Jackson, and Louise O'Brien. "Father absence and adolescent development: a review of the literature." Journal of Child Health Care 10.4 (2006): 283-295. 
Goldenberg, Herbert, and Irene Goldenberg. Family therapy: An overview. Cengage learning, 2012.

Hetherington, E. Mavis, and Jan L. Deur. "The effects of father absence on child development." Young Children (1971): 233-248.

Johnson, Priscilla, review of Dinner at the Homesick Restaurant, School Library Journal, 28 (August 1982)

Jurma, Anda Maria. "Impact of divorce and mother's psychological well-being on children's emotional, behavioral, and social competences." Revista de Cercetare şi Intervenţie Socială 48 (2015): 69-82.

Kadushin, Alfred. "Single-parent adoptions: An overview and some relevant research." Social Service Review 44.3 (1970): 263-274.

Kerr, Michael E. and Murray Bowen. Family Evaluation. WW Norton \& Company, 1988.

Kelly, Joan B., and Robert E. Emery. "Children's adjustment following divorce: Risk and resilience perspectives." Family relations 52.4 (2003): 352-362.

Kopsztejn, Maria. "FAMILY AND ITS PROBLEMS." Zeszyty Naukowe Wyższej Szkoty Humanitas. Pedagogika 10 (2015): 23-49.

Jamiolkowski, Raymond M. Coping in a dysfunctional family. The Rosen Publishing Group, 1998.

Johnson, Benjamin E., and Wendel A. Ray. "Family systems theory." Encyclopedia of Family Studies (2016): 782-787.

Levy-Shiff, Rachel. "The effects of father absence on young children in motherheaded families." Child Development(1982): 1400-1405.

Longabaugh, Richard. "Mother behavior as a variable moderating the effects of father absence." Ethos 1.4 (1973): 456-465. 
Luepnitz, Deborah Anna. The family interpreted: Feminist theory in clinical practice. Basic Books, 1988.

MacArthur, James D. "The functional family." Utah: Brigham Young University (2000).

Mackey, Wade C., and Bonnie Mackey. "The presence of fathers in attenuating young male violence: Dad as a social palliative." Marriage \& Family Review 35.12 (2003): 63-75.

McGraw-Hill Concise Dictionary of Modern Medicine. 2002 by The McGraw-Hill Companies, Inc.

McLanahan, Sara, Laura Tach, and Daniel Schneider. "The causal effects of father absence." Annual review of sociology39 (2013): 399-427.

Mott, Frank L., Lori Kowaleski-Jones, and Elizabeth G. Menaghan. "Paternal absence and child behavior: Does a child's gender make a difference?" Journal of Marriage and the Family (1997): 103-118.

Norton, Susan. "Crossing Borders in Anne Tyler's Fiction." (2003).

Pachauri, Pooja Rathiand. "Problems faced by divorced women in their pre and post-divorce period: A sociological study with reference to District Meerut." Journal of Pharmacognosy and Phytochemistry 7.1 (2018): 207-212.

Parish, Thomas S., and Bruno M. Kappes. "Impact of father loss on the family." Social Behavior and Personality: an international journal 8.1 (1980): 107112.

Parrillo, Vincent N., ed. Encyclopedia of social problems. Sage Publications, 2008.

Tyler, Anne. Dinner at the Homesick Restaurant: A Novel. Vintage, 1996.

Vaughan, D. Uncoupling. New York: Ballantine Books, 1996.

Winek, Jon L. Systemic family therapy: From theory to practice. Sage, 2009. 